\title{
Algal Indication of Climatic Gradients
}

\author{
Sophia Barinova ${ }^{1,}$, , Viktor Gabyshev ${ }^{2}$, Mariyo Boboev ${ }^{3}$, Lali Kukhaleishvili ${ }^{4}$, Olena Bilous ${ }^{5}$ \\ ${ }^{1}$ Institute of Evolution, University of Haifa, Mount Carmel, Haifa, Israel \\ ${ }^{2}$ Institute for Biological Problems of Cryolithozone SB RAS, Yakutsk, Russia \\ ${ }^{3}$ Khatlon Scientific Center Academy of Sciences of the Republic of Tajikistan, Kulob-town, Tajikistan \\ ${ }^{4}$ Tbilisi Botanical Garden and Institute of Botany, Tbilisi, Georgia \\ ${ }^{5}$ Institute of Hydrobiology of NAS of Ukraine, Kiev, Ukraine
}

\section{Email address:}

barinova@research.haifa.ac.il (S. Barinova)

\section{To cite this article:}

Sophia Barinova, Viktor Gabyshev, Mariyo Boboev, Lali Kukhaleishvili, Olena Bilous. Algal Indication of Climatic Gradients. American Journal of Environmental Protection. Special Issue: Applied Ecology: Problems, Innovations. Vol. 4, No. 3-1, 2015, pp. $72-77$. doi: 10.11648/j.ajep.s.2015040301.22

\begin{abstract}
Bio-indication is only possible because algal communities respond to environmental changes in a consistent way. In particular, the vectors of algal changes over latitudes and altitudes are well correlated with respective climatic gradients. The relationships between biotic and climatic changes are insufficiently studied so far, but regularities are analyzable provided the adequate geographic scale. Thus the impact of seasonality requires ecological study of the aquatic object as a whole or a considerable part of it. For the gradient analysis of altitudinal changes the sampling data must cover a region of diverse relief, whereas latitudinal gradients are traceable of sizeable parts of continents encompassing different climatic zones. In our studies, the impact of temperature changes is invariably significant when revealed with the help of bio-indication analysis. In the boreal realm, algal development most typically show three seasonal peaks correlated with the dynamics of ice cover, whereas two to single peak are distinguished down the latitudes. The latitudinal dynamics is fairly obvious in the quantitative relationships between diatoms, green, golden algae, and Infraspecies-Species variability. With climatic stress ascending to the north, the role of diatoms, but in the high Arctic regions drops significantly. The Infraspecific variability index increases from 1.09 up to 1.42. To the south, over the mountainous areas of Tajikistan, Georgia, Mediterranean and India, diatoms consistently decrease over the altitudinal range 200 - 2500 meters, while the other algal groups betray a less significant variation. Such regularities are more obvious with statistical correlation of climatic variables and freshwater algal diversity. Thus the distribution of phytoplankton species in the rivers of Yakutia and Chukotka over the gradient of DHI index and the duration of the ice free period is controlled by sun light intensity in the first place, but also reflects variation in the climatic stress resistance, the most prominent in the case of diatom algae.
\end{abstract}

Keywords: Freshwater Algae, Diversity, Ecology, Bio-Indication, Altitude, Latitude, Climate Change

\section{Introduction}

Climate is a complex dynamic system, and climate change is a cumulative effect of many interlinked natural processes. Sun luminosity is involved as well as the terrestrial factors related to the Earth rotation and revolution variables [1]. The long term periodicity is related to the rotation velocity effect on the mass distribution in the earth's crust and mantle [2] the hydrosphere effect producing a lower scale fluctuation [3], superimposed by the polar ice cap autocycles, with multiple feedbacks. The $\mathrm{CO} 2$ greenhouse effect among them falls under multiple regulation of hydrosphere, rock weathering, soil outgassing, and biomass production jointly damping fluctuations to a low amplitude cyclicity [2].

However, climatic variables can be considered relatively stable relative to the developmental time scale of algal communities. Factors such as latitude or altitude gradient, are not only linked to the main climatic characteristics, but also the key players in shaping factors of biota diversity as recognized in the current stage of biome evolution.

The existence and use of active systems of bio-indication confirms that algal communities respond to environmental change. The climatic conditions of the environment have a well-defined gradient when considered over a range of latitudes or altitudes of the habitats. Investigation of the relationship of freshwater algal communities with climatic 
gradient is still in the early stage [4,5], but it is already clear that community response has a certain regularity. The scale of the investigated region corresponds to the problem. Thus, to identify seasonality it can be the whole aquatic object or a portion thereof. For an altitudinal gradient it is the region comprising a steep topographic range as in the mountains. For the latitudinal gradient it has to be part a land mass of a considerable range of climatic gradient.

The aims of the current study are to reveal the response of high mountains and high latitude algal communities in Eurasia to the latitude and altitude-related climatic condition of its habitats. Thus, we try to implement diverse bio-indicational and statistical methods which represent some new approaches in freshwater algal diversity analysis of climate impact.

\section{Study Area and Methods}

Material for this study comes from the last twenty years of research in the rivers and lakes of Eurasia [6-17].

The main approach for algal diversity summarizing data comes from [18].

To identify the main distribution patterns of algae diversity over climatic gradients we used statistical methods that are those recommended by [19] for development of floristic and taxonomic studies, namely, the CANOCO Program [20] for Representational Difference Analysis (RDA) and Canonical Correspondence Analysis (CCA) [21,22] , GRAPHS program [23] for comparative floristic evidence, Statistica 7.0 Program for Stepwise regression analysis and Distance Weighted Least Squares calculation, and statistical techniques included in the PRIMER-v5 package [24] for the comparative inter-regional analysis of taxonomic diversity [6].

\section{Results and Discussions}

We have found that one of the most important climatic factors is temperature [25] and the aquatic algal communities react to changes in water temperature and sometimes it can only be seen through bio-indication analysis [9]. And, if in the boreal region of algal development has three peaks during free of ice-period [10], in the more southern areas it is about two [6], or southern up to one $[11,12]$.

\subsection{Latitudinal Distribution}

So, in boreal regions seasonal fluctuations are regulating algal growth in respect to the level of nutrient supply. The fluctuations of the phytoplankton biomass show seasonal peaks in spring, autumn, and summer, associated with the main feature of boreal waterbodies - the complexity of their thermal structure [10]. At the same time, relationships between algal species diversity and water temperature can be revealed when we compare seasonal communities, in particular the summer ones which are the most rich and diverse. It can be seen in Fig. 1 for one of the large European rivers in Eurasian Boreal Realm, the Southern Bug River phytoplankton communities [12]. This approach lets us to avoid the impact of seasonality fluctuation to calculation result. In this case we choose summer phytoplankton communities for calculation of climatic parameters impact on the algal taxonomic structure and productivity.

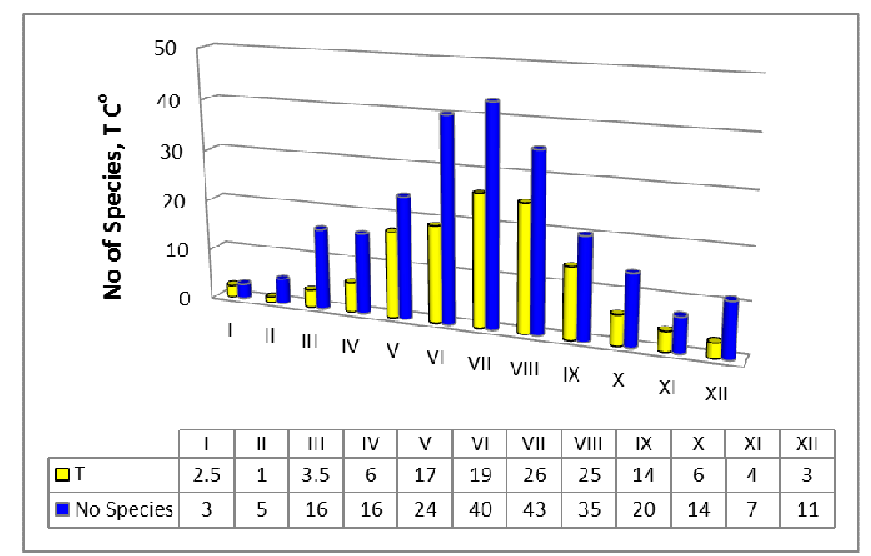

Figure 1. Monthly water temperature and phytoplankton species richness in the Southern Bug River.

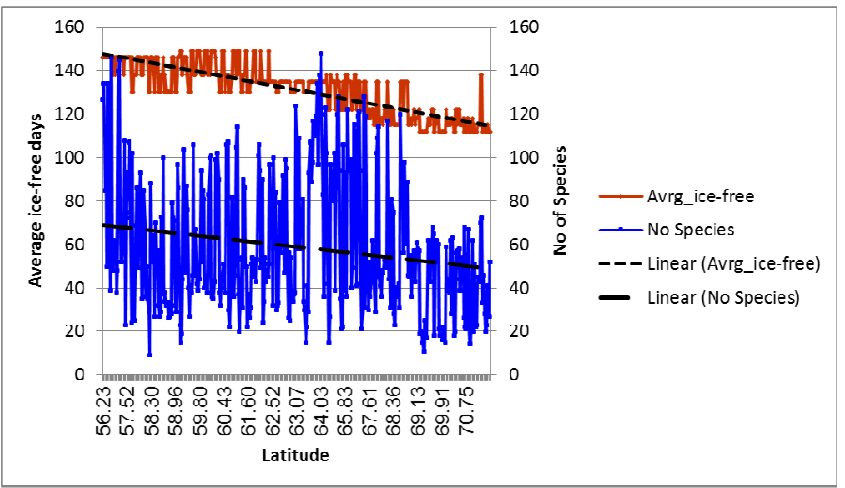

Figure 2. Distribution of ice-free days and species richness in rivers of Yakutia and Chukotka over latitude gradient.

As has been revealed, the latitudinal climate change from boreal region to the Arctic affects the distribution of diatoms, green and golden algae (Fig. 2) [13]. With the increase climatic stress the species richness sufficiently decreased with the number of ice-free days decreasing because the algal cells need photosynthetic radiation for it grows.

\subsection{Altitudinal Distribution}

Among the southern regions of Mediterranean, Tajikistan, Georgia, and India witness a decrease of diatoms with altitude in the interval from 200 to 2500 meters, with the other groups scarcely affected.

So, in the Eastern Mediterranean where altitude gradient changed from $440 \mathrm{~m}$ below sea level up to $2200 \mathrm{~m}$ above sea level (a.s.l.), the role of green algae and cyanobacteria is more significant than the diatoms (Fig. 3) [14].

Algal distribution in the Vakhsh River Basin shows the importance of altitude and associated climatic gradients (Fig. 4). Can be seen that the role of diatoms in aquatic habitats of the Pamir Mountains is significantly decreased with increasing of habitat altitude [15]. 
Similar distribution we revealed for the Caucasus Mountain algal diversity (Fig. 5) where diatoms also are a climate indicative group of algae $[7,8]$.

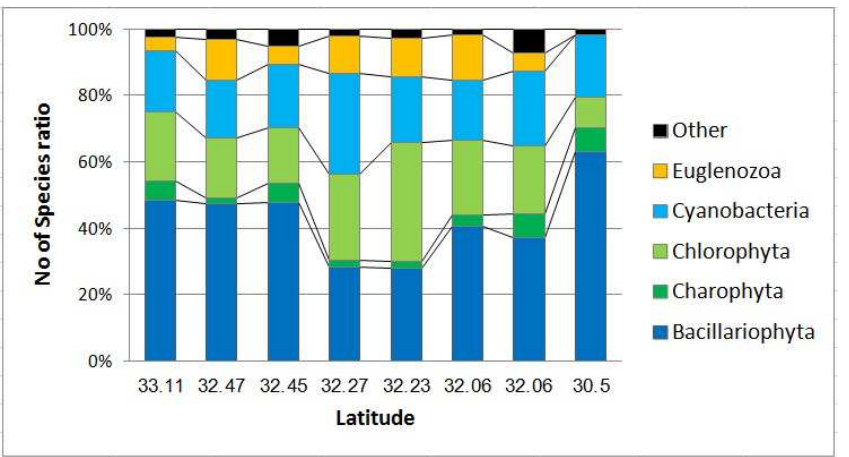

Figure 3. Split Distribution of algal species richness in rivers of Eastern Mediterranean over latitude.

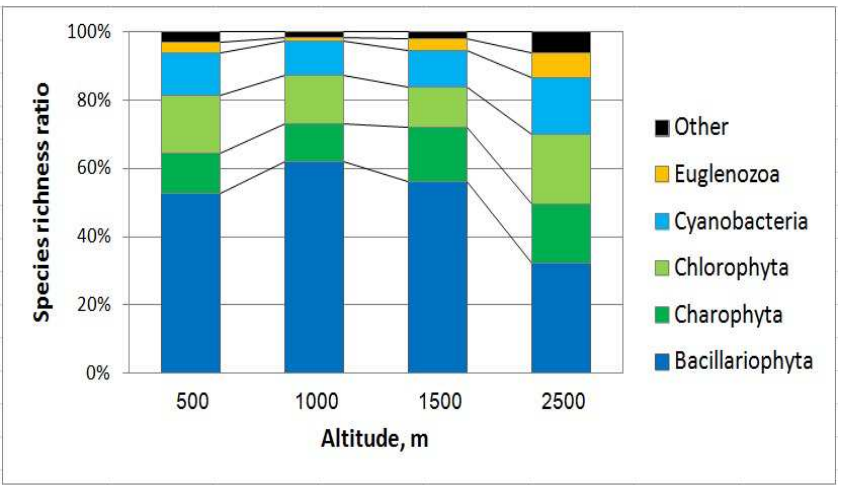

Figure 4. Distribution of algal species richness in the Vakhsh River Basin habitats over latitude.

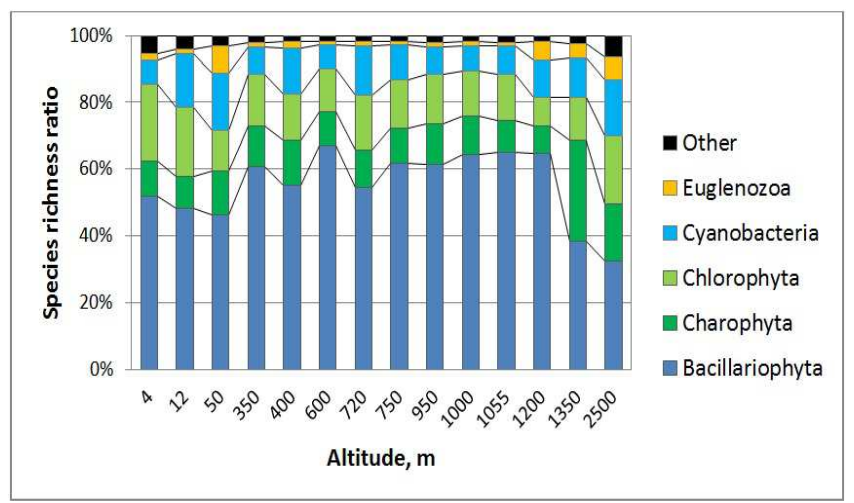

Figure 5. Distribution of algal species richness in Caucasus Mountain aquatic habitats over latitude

Climate influenced not only species richness in algal communities but also production variables such as abundance and biomass of riverine phytoplankton [13]. This let us to assume that sunlight intensity and environmental temperature is the major regulating factors for gamma-diversity distribution patterns.

Revealed relationship of algal diversity distribution over altitude of habitats seems like natural and therefore we can assume that the diatom algae can be marker taxa for the climatic influence on bio-diversity change.

\subsection{Salinity - Global Climate Warming Relationships}

The main influence on the Central Eurasia lakes comes from cyclic changes of moisture in the region, happening along with global warming. We revealed the statistically significant correlation between salinity of the Balkhash Lake [26], the forty eight northern Kazakhstan lakes [27], Ukrainian saline lakes [28], and water bodies of the Eastern Mediterranean [6] and the long-term dynamics of algal species richness which decreased with increasing of water salinity. Importance of salinity for productivity algal communities let us to assume that climate warming that provoke salinity increasing as a result of evaporation is especially high in arid and semi-arid regions of planet. Decreasing of species diversity and aquatic community productivity can decrease not only total biomass production but also increase $\mathrm{CO}_{2} / \mathrm{O}_{2}$ ratio in atmosphere when global temperature will increase.

\subsection{Statistical Approaches}

Statistical methods further clarify the relationship of climate change and diversity of algae. Thus, the distribution of phytoplankton species in the rivers of Yakutia and Chukotka on a gradient index DHI (Dynamic Habitat Index) [29] and the ice-free period shows the importance of sunlight intensity, which is understandable, but also inhibition of algae in the harsh conditions of the Arctic, can be traced more significant role in the communities of diatoms lower latitudes [13].

Statistical methods that we implemented to our material help us to reveal not only real data relation but also have prognostic properties. So, Fig. 6 shows the importance of DHI index and sunlight intensity for algal species richness.

Fig. 7 shows a decreasing role of diatom algae in the high-latitude Eurasian communities and correlated with the Geo-association index of latitudinal distribution combined with the direction of the river flow [13].

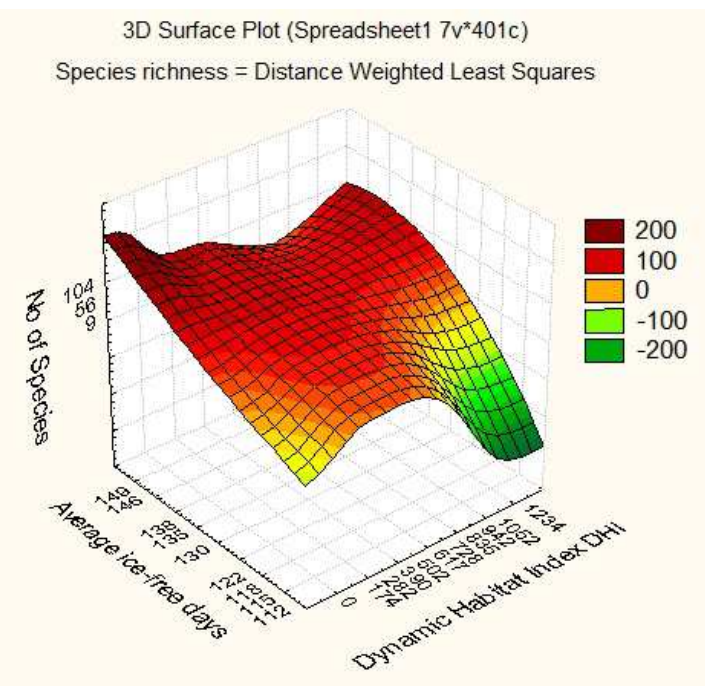

Figure 6. Distribution pattern of phytoplankton species richness in phytoplankton of the large Eastern Siberia rivers over sunlight intensity (Average ice-free days) and landscape sensitivity (DHI). 


\section{D Surface Plot (Spreadsheet1 10v*303c) \\ No Species $=$ Distance Weighted Least Squares}

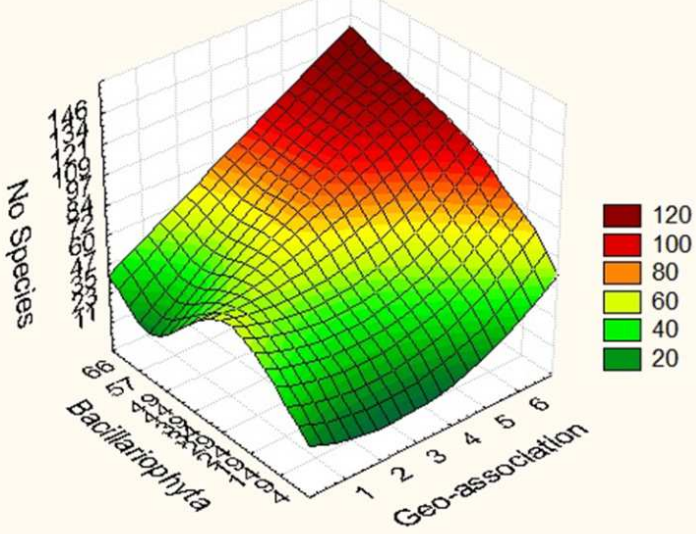

Figure 7. Distribution pattern of phytoplankton species richness in the large Eastern Siberia rivers over diatom numbers and Geo-association Index

3D Surface Plot (Spreadsheet2 56v*409c)
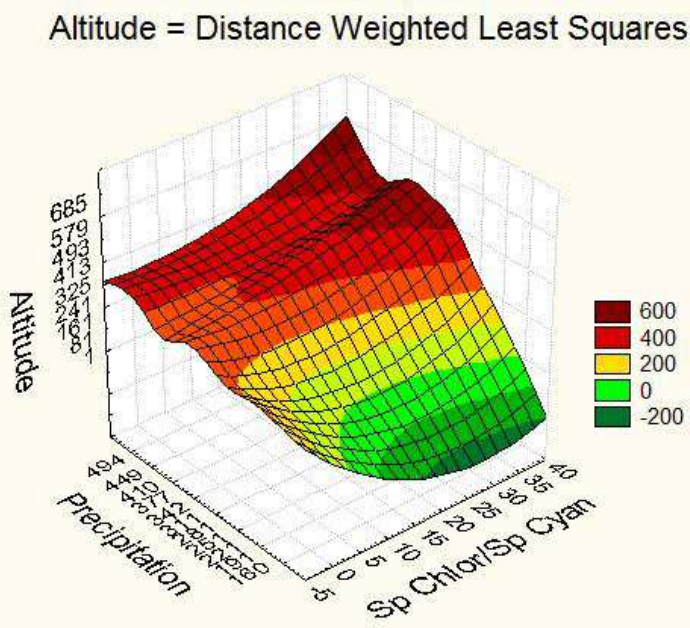

Figure 8. Altitude, precipitation and Chlorophyta/Cyanobacteria ratio relationships in the large Eastern Siberia rivers.

Despite the fact that the diatoms represent conspicuous response to climatic impact, indication of climate change is also possible with correlation of separate taxonomic groups. Fig. 8 show that green algae species richness increased with increasing of habitat altitude and altitude-related precipitation rate, while cyanobacteria decrease [13].

\subsection{Infraspecific Variability}

A notable feature of algal taxonomic structure in water bodies of southern regions of Eurasia is a large proportion of monomorphic species comparative with other algal floras of Europe, central - northern Asia and North America.

Such exceptionally low infraspecies variability might have been related to recent climatic instability and anthropogenic impacts that obliterated microhabitat differentiation and promoted highly tolerant monomorphic populations. In the both cases the Index Infraspecies/Species variability that the decrease in Hemisphere from north to south [30] can be related with climate changes and can be used as criteria of future warming. We added some new information from our recent research and represent it in Fig. 9.

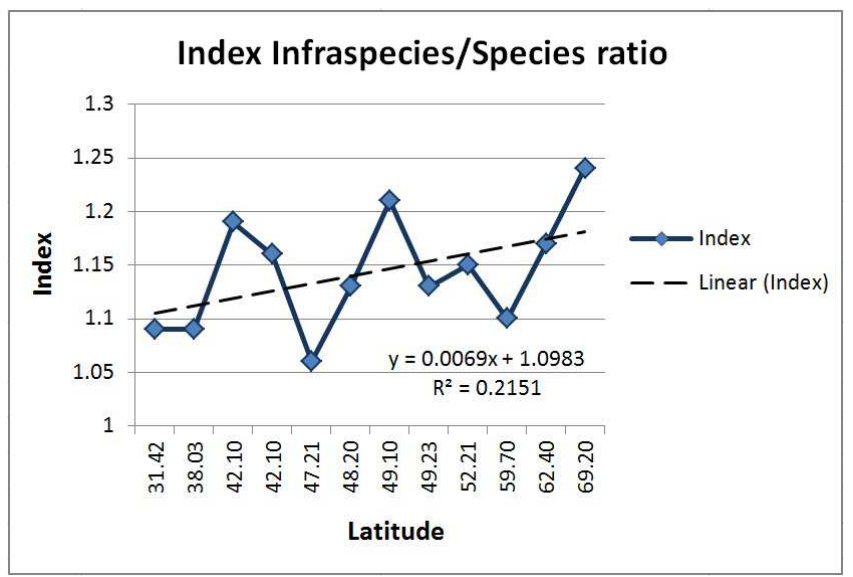

Figure 9. Index Infraspecies/Species variability over latitude of habitats in Eurasia.

Trend line shows sure rising of Infraspecies/Species Index due to the latitude of algal habitat. Remarkable that outstanding point such as 1.19 (Georgian Natural Reserves), 1.21 (Diatoms of Europe), 1.21 (Viliuy Reservoir, Yakutia) are summarized large sets of long-term scale information [30]. The Tajik Depression flora has even 1.43 Index [15], but it is not only large scale regional and time series, but also high mountain biome.

\section{Conclusion}

Algal bio-indication remains an efficient method for assessing not only water quality, but also climatic influence, involving the wide range of indicators and based on the ecological preferences of the species. Assessment of climate impacts on aquatic ecosystems, held the first time for gamma-diversity, shows the importance of bio-indication for the understanding of regional and global changes.

Recent studies show that the data on the diversity and ecology of algae can identify the climatic gradients influence, as well as reveals groups of aquatic organisms which are most clearly reflect their.

The impact of latitudinal and altitudinal temperature changes is invariably significant when revealed with the help of bio-indication analysis.

Infraspecies/Species Index is remarkable rising with latitude of algal habitat in the continent. The latitudinal climate change from boreal region to the Arctic affects the distribution of different groups of algae when the species richness sufficiently decreased with decreasing of number of ice-free days because the algal cells needs photosynthetic radiation for it grows.

The role of green algae and cyanobacteria is more significant than the diatoms with altitude of habitat rising.

Climate influenced not only species richness in algal communities, but also production variables such as abundance 
and biomass, where the diatom algae can be marker taxa for the climatic influence on bio-diversity change. This lets us to assume that sunlight intensity and environmental temperature is the major regulating factors for gamma-diversity distribution patterns.

We revealed the statistically significant correlation between salinity and the long-term dynamics of algal species richness which decreased with increasing of water salinity. Therefore, we assumed that the main influence on the Central Eurasia lakes comes from cyclic changes of moisture in the region, happening along with global warming.

Statistical methods that we implemented to our material helps us to reveal not only of the real data relation, but also having of prognostic properties showing the importance of sunlight intensity and altitude-related precipitation rate for algal species richness in purpose of revealing climatic trends.

\section{Acknowledgements}

We are thankful to the Israeli Ministry of Absorption that partly funded this research.

\section{References}

[1] Krassilov, V., Barinova, S. (2013). Sea level - geomagnetic polarity correlation as consequence of rotation geodynamics. Earth Science, 2(1): 1-8.

[2] Krassilov, V.A. (2003). Terrestrial Palaeoecology and Global Change. Pensoft: Sophia, 464 pp.

[3] Krassilov, V., Barinova, S., Rybnikov, S. (2014). Rotation Forcing of Tectonics and Climate. Earth Sciences, 3(3): 68-75. doi: $10.11648 /$ j.earth.20140303.11

[4] Barinova, S. Nevo, E. (2012). Climatic and pollution impact on algal diversity of the freshwater ecosystems in Eurasia. In: Climate Change and Impacts. AcademyPublish.org, WY, USA: pp. 16-50.

[5] Medvedeva, L.A., Barinova, S., Semenchenko, A.A. (2012). Use of Algae for Monitoring Rivers in the Monsoon Climate Areas (Russian Part of Asian Pacific Region). International Journal of Environment and Resource, 1(1): 39-44.

[6] Barinova, S. (2011). Algal diversity dynamics, ecological assessment, and monitoring in the river ecosystems of the eastern Mediterranean. Nova Science Publishers, New York, USA, 363 pp.

[7] Barinova, S.S., Kukhaleishvili, L., Nevo, E., Janelidze, Z. (2011). Diversity and ecology of algae in the Algeti National Park as a part of the Georgian system of protected areas. Turk. J. Bot., 35 729-774.

[8] Barinova, S., Kukhaleishvili, L. (2014). Diversity and ecology of algae and cyanobacteria in the Aragvi River, Georgia. The Journal of Biodiversity. Photon, 113: 305-338.

[9] Klochenko, P., Shevchenko, T., Barinova, S., Tarashchuk, O. (2014). Assessment of the ecological state of the Kiev Reservoir by the bioindication method. Oceanological and Hydrobiological Studies, 43(3): 228-236.
[10] Barinova, S., Stenina, A. (2013). Diatom diversity and ecological variables in the Arctic lakes of the Kostyanoi Nos Cape (Nenetsky Natural Reserve, Russian North), Plant Biosystems, 147(2):

DOI:10.1080/11263504.2012.749956

[11] Barinova, S., Keshri J.P., Ghosh S., Sikdar J. (2012). The influence of the monsoon climate on phytoplankton in the Shibpukur pool of Shiva temple in Burdwan, West Bengal, India. Limnological Review, 2(2): 47-63. DOI 10.2478/v10194-011-0044-y

[12] Bilous, O., Barinova, S., Klochenko, P. (2013). Climatic influence on the phytoplankton communities of the upper reaches of the Southern Bug River (Ukraine). Transylvanian Review of Systematical and Ecological Research. The Wetland Diversity, 15(2): 61-86.

[13] Barinova, S., Gabyshev, V., Gabysheva O. (2014). Climate Impact on Freshwater Biodiversity: General Patterns in Extreme Environments of North-Eastern Siberia (Russia). British Journal of Environmental and Climate Change, 4(4): 387-407.

[14] Barinova, S., Krassilov, V.A. (2012). Algal Diversity and Bio-indication of Water Resources in Israel. International Journal of Environment and Resource, 1(2): 62-72.

[15] Barinova, S., Boboev, M., Hisoriev H. (2015). Climate impact on freshwater algal diversity of the South-Tajik Depression in a high mountainous extreme environment. Turk. J. Bot., 39(1), in press

[16] Barinova, S., Naiz Ali, Barkatullah, Sarim, F.M. (2013). Ecological Adaptation to Altitude of Algal Communities in the Swat Valley (Hindu Cush Mountains, Pakistan). Expert. Opin. Environ. Biol., 2(2): 1-15. doi:10.4172/2325-9655.1000104

[17] Barinova, S.S., Nevo, E. (2010). The Upper Jordan River algal communities are evidence of long-term climatic and anthropogenic impacts. J. Water Resource and Protection, 2: 507-526.

[18] Barinova, S. (2013). Multilevel approach in biodiversity analysis of freshwater algae. Expert Opinion on Environmental Biology, 2(2): http://dx.doi.org/10.4172/2325-9655.1000e106

[19] Heywood, V. (2004). Modern approaches to floristics and their impact on the region of SW Asia. Turk. J. Bot., 28: 7-16.

[20] ter Braak, C.J.F., Šmilauer, P. (2002). CANOCO Reference Manual and CanoDraw for Windows User's Guide: Software for Canonical Community Ordination (version 4.5). Ithaca: Microcomputer Power Press.

[21] ter Braak, C.J.F. (1987). The analysis of vegetation-environment relationships by canonical correspondence analysis. Vegetatio 69: 69-77.

[22] ter Braak, C.J.F. (1990). Interpreting canonical correlation analysis through biplots of structural correlations and weights. Psychometrica 55: 519-531.

[23] Novakovsky, A.B. (2004). Abilities and base principles of program module "GRAPHS". Scientific reports of Komi Scientific Center, Ural Division of the Russian Academy of Sciences 27: 1-28. (In Russian).

[24] Clarke K.R., Gorley R.N. (2001). PRIMER v5: User Manual/ Tutorial. PRIMER-E, Plymouth. 
[25] Barinova, S.S., Nevo, E. (2012). Climatic and pollution impact on algal diversity of the freshwater ecosystems in Eurasia. In: Climate Change and Impacts, AcademyPublish.org, Wyoming, U.S.A: pp. 16-56.

[26] Krupa, E., Slyvinskiy, G., Barinova, S. (2014). The effect of climatic factors on long-term dynamics of phytoplankton, zooplankton and macrozoobenthos of the Balkhash Lake (Kazakhstan, Central Asia). Advanced Studies in Biology, 6(3): 115-136. http://dx.doi.org/10.12988/asb.2014.4523

[27] Barinova, S.S., Bragina, T.M., Nevo, E. (2009). Algal species diversity of arid region lakes in Kazakhstan and Israel. Community Ecology, 10(1): 7-16.
[28] Klymiuk, V., Barinova, S., and Lyalyuk, N. (2014). Diversity and Ecology of Algal Communities from the Regional Landscape Park "Slavyansky Resort", Ukraine. Research and Reviews: Journal of Botanical Sciences, 3(2): 9-26.

[29] Coops, N.C., Wulder, M.A., Duro, D.C., Han, T., Berry, S. (2008). The development of a Canadian dynamic habitat index using multi-temporal satellite estimates of canopy light absorbance. Ecol Indicators, 8: 754-766. DOI: 10.1016/j.ecolind.2008.01.007.

[30] Barinova, S. (2011). The effect of altitude on distribution of freshwater algae in continental Israel. Current Topics in Plant Biology, 12: 89-95. 